\title{
An empirical study on the impact of digital economy development on the upgrading and optimization of industrial structure
}

\author{
Chao Zhang ${ }^{1, *}$ \\ ${ }^{1}$ Accounting Department of Beijing Jiaotong University, Haidian District, Beijing, China
}

\begin{abstract}
As an important driving force and new kinetic energy, digital economy is promoting the development of economy in the direction of high quality, and brings new opportunities and challenges to the development of real economy and the upgrading and optimization of industrial structure. Therefore, this paper measures the digital economy from the two aspects of "digital industrialization" and "industrial digitization", and selects the data of 30 provinces and cities from 2012 to 2019 to empirically study its impact on the upgrading and optimization of China's industrial structure. Through the research, it is found that digital economy can indeed improve the level of upgrading and optimization of industrial structure. At the same time, further analysis shows that the degree and mechanism of improving the level of eastern, central and western regions will be different according to different regions. Finally, according to the research results, this paper puts forward some countermeasures and suggestions to promote the development of digital economy and the optimization and upgrading of industrial structure in China.
\end{abstract}

\section{Introduction}

"The 14th Five-Year Plan" puts forward: digital economy has become the core driving force of development, and has made outstanding contributions in promoting high-quality economic development, improving reform efficiency, and promoting the transformation and upgrading of the real economy. Therefore, it is necessary to promote the healthy development of platform economy and sharing economy, promote digital industrialization and industrial digitization, and promote the deep integration of digital economy and real economy, it points out the direction for the development of digital economy in China.

At present, China is actively transforming the driving force of growth, changing the form of development and optimizing the economic structure in order to achieve the optimization and upgrading of industrial structure. In this process, the integration of digital economy and real economy provides opportunities and challenges for promoting high-quality economic development. Therefore, we should give full play to the advantages of digital economy, drive the development of real economy, reduce the damage and impact on real economy, and seize the important driving force and new kinetic energy of digital economy.

Since China's economy entered the "new normal" of development, the focus of economic development has shifted from the development of low-end industries and heavy industries to the development of medium and high-end industries and emerging industries, and innovation is the core driving force to promote the upgrading and optimization of industrial structure. China is in the development stage of "Internet plus", and a large number of digitalized technologies and traditional industries are deeply integrated to promote economic growth and efficiency improvement of all trades and industries, bringing opportunities and challenges for upgrading and optimizing industrial structure. Therefore, we should seize the new momentum of digital economy, clarify its influence mechanism on the optimization and upgrading of China's industrial structure, and explore the relevant measures to achieve the optimization and upgrading of industrial structure, so as to provide a theoretical basis for the realization of high-quality economic development.

Therefore, this paper measures the digital economy from the two aspects of "digital industrialization" and "industrial digitization", and selects the data of 30 provinces and cities from 2012 to 2019 to empirically study its impact on the upgrading and optimization of China's industrial structure. At the same time, further analysis by region, to further clarify the differences of the influence mechanism of the development of digital economy on the optimization and upgrading of industrial structure in different regions. Finally, the method of replacing independent variables is used to test the robustness to ensure the accuracy of the research conclusions. 


\section{Literature Review}

In 1996, the American scholar Tapscott first pointed out the meaning of digital economy, but he mainly studied the new situation of economic system after the popularization of information superhighway in the United States, and did not clearly explain the meaning of digital economy. With the development of the times, Brent $r$ Moulton proposed the scope of digital economy, including computer, e-commerce, communication technology and so on. In 1988, "the emerging digital economy" pointed out the meaning of the form of digital information industry and its significant impact on economic development. After that, each country puts forward its own explanation for the concepts of digital economy, information economy and virtual economy, aiming to take the information and communication technology industry as the core of the development of digital economy and realize the new generation of economic development.

In the G20 digital economy development and cooperation initiative, China has clearly put forward the concept of Digital Economy: a series of economic activities with the use of digital knowledge and information as the key production factors, modern information network as an important carrier, and the effective use of information and communication technology as an important driving force for efficiency improvement and economic structure optimization, covering digital industrialization, information technology, information technology and information technology Industrial digitization and other major fields. Therefore, this paper mainly explores the influence of digital economy on the upgrading and optimization of industrial structure from two aspects of digital industrialization and industrial digitization.

Through studying the relevant literature, we can find that the research on digital economy from the industry mainly includes traditional industries based on communication technology, Internet industry and new business forms and new models based on digital technology, namely digital industrialization and industry digitization ${ }^{[1]}$. Among them, industry digitization is the initiative to promote the high-quality development of economy. Most scholars have studied the influence of digital economy on traditional industries from the perspective of first, second and third industries, and few literatures have discussed the influence of digital economy on the upgrading and optimization of industrial structure $^{[2]}$. The research shows that China is developing to medium and high-end industries and emerging industries. It is necessary to take digital economy as an important driving force and innovation as the core to carry out digital reform on traditional industries and real economy, and comprehensively improve the upgrading and optimization of industrial structure. A few scholars quantitatively study the influence of digital economy on the upgrading and optimization of industrial structure. Chen Xiaohui and others (2020) think that digital economy has marginal increasing effect on the adjustment and optimization of industrial structure in China ${ }^{[3]}$. Li Xiaozhong and Wu Jiaxu (2020) believe that there is a long-term, sustained, positive and non-equal dynamic interaction between digital economy and industrial structure transformation and upgrading ${ }^{[4]}$.

To sum up, the research on the development of digital economy and the optimization and upgrading of industrial structure is still in its infancy. Most of the existing researches mainly focus on the development of certain traditional industries and information industry, and mostly use the form of qualitative analysis, There are few literatures based on theoretical model and empirical analysis to study the impact of digital economy development on the optimization and upgrading of industrial structure, and the existing results have not been combined with the core connotation of digital economy. Therefore, this paper studies the influence of digital economy on the upgrading and optimization of industrial structure from two aspects of digital industrialization and industrial digitization.

\section{Research design}

\subsection{Hypothesis}

Digital economy includes digital industrialization and industrial digitization. Digital industrialization is the leading industry of digital economy development, also known as the basic part of digital economy, namely information and communication industry, which provides technology, services, products and solutions for the development of digital economy. It is bred in big data, cloud computing and other digital technology continues to mature, and according to the new needs of the development of market economy, applied to all walks of life, is a new business logic and business operation mode. It mainly includes information and communication industry and its derived new industries, new formats and new models. Information and communication industry, including electronic information manufacturing industry, telecommunication industry, software and information technology service industry, and Internet industry is an important industry in digital economy and actively promotes high-quality economic development. New industries, new formats and new models mainly include "sharing economy", "digital payment" and "cross-border e-commerce" relying on information technology. The development of digital economy promotes the development of intelligence intensive, technology intensive and knowledge intensive industries, which is conducive to the improvement of industrial structure.

At present, digital technology is constantly innovating, integrating and widely used. New industries, new formats and new models are in a blowout growth state, which provides opportunities and challenges for the upgrading and optimization of industrial structure. In recent years, with the rise of live broadcasting with goods, the e-commerce industry is booming. In 2019, the national online retail sales have reached 10.63 trillion yuan, of which the online retail sales of physical goods is 8.52 trillion-yuan, accounting for $20.7 \%$ of the total retail sales of social consumer goods. Therefore, digital 
industrialization symbolizes the development direction and the latest achievements of the new generation of information technology. With the continuous breakthrough of digital technology, a new digital industry system with software definition and data-driven is accelerating to form, which plays a positive role in the optimization and upgrading of China's industrial structure. Therefore, the first hypothesis of this paper is put forward:

Hypothesis 1: Digital industrialization can promote the emergence of new industries and new formats, provide necessary development support for traditional industries, and then drive the optimization and upgrading of industrial structure.

Industry digitization is the improvement of production quantity and efficiency brought by the application of digital technology in traditional industries, and its new output constitutes an important part of digital economy. Digital economy is not a digital economy, but an integrated economy. The real economy is the foothold, and high-quality development is the general requirement. Industry digitization includes but is not limited to new industries, new models and new formats of industrial Internet, integration of industrialization and industrialization, intelligent manufacturing, internet of vehicles, platform economy and other integrated industries. Industry digitization highlights the integration of traditional industries and digital technology, which can promote the development of traditional industries to intelligent and agile, provide technical support and development platform for traditional industries, improve production efficiency and management level, optimize resource allocation, and promote the transformation and upgrading of industries. At the same time, industry digitization can realize the innovation and development of the industry. Applying digital technology to traditional industries can effectively break through the original mode of thinking, realize subversive reform from the use of factors, production mode, business mode and other fields, and promote the integration and development of industries ${ }^{[5]}$.

Therefore, accelerating the development of Internet of things, cloud computing and other digital technologies, and promoting their deep integration with traditional industries, will help to improve the quality of industrial development, innovate industrial development mode, and then promote the optimization and upgrading of industrial structure.Based on this, this paper puts forward the second hypothesis:

Hypothesis 2: Industrial digitization can promote the comprehensive upgrading of traditional industries and accelerate the development of inter industry integration, and drive the optimization and upgrading of industrial structure.

\subsection{Data source and variable description}

In view of the incomplete data of some years in Xinjiang, Hong Kong, Macao and Taiwan, this paper only selects the panel data of the other 30 provinces for empirical research. The sample data are from the websites of the
National Bureau of statistics, the Ministry of industry and information technology and the Ministry of Commerce from 2012 to 2019, the China Statistical Yearbook, the China Information Yearbook and the statistical yearbooks of relevant provinces (regions and cities).

The explained variable is the level of industrial structure optimization and upgrading (UIS). At present, the measurement indexes of industrial structure optimization and upgrading mainly include the rationalization index of industrial structure, the advanced index of industrial structure and the upgrading index of industrial structure. The upgrading index of industrial structure can more intuitively describe the current situation of industrial structure optimization and upgrading in a region. Therefore, this paper refers to Xie Tingting et al. (2017) to measure the optimization and upgrading of industrial structure, and uses the industrial structure upgrading index to express the development trend of industrial structure in each province ${ }^{[6]}$. The specific calculation method is as follows:

$$
U T S=\sum_{i=1}^{3} y_{i} * i
$$

$\mathrm{y}_{\mathrm{i}}$ is the proportion of the three industries in GDP in each province, $i$ are 1, 2 and 3 respectively, representing the primary, secondary and tertiary industries. The value of industrial structure upgrading coefficient is in the range of $[1,3]$, and the closer to 3 , the higher the degree of industrial structure upgrading is.

The core explanatory variables include the level of digital industrialization and the level of industrial digitization.According to the white paper on China's digital economy development and employment (2019) issued by China information and Communication Research Institute, the scale and development of Internet and related service industries are important indicators to measure digital industrialization. Therefore, Internet broadband access port (Internet) is selected as the representative indicator of digital industrialization level.

At present, with the promotion and popularization of digital technology, great changes have taken place in the traditional industry. Artificial intelligence, online education, live delivery, intelligent medical and so on have entered people's daily life. Digital technology has obviously promoted the rapid development of industry digitization. Therefore, according to the classification system of China's three industries, the ratio of ecommerce sales to GDP (ds) is selected as the representative index of industry digitization.

In this paper, four control variables are selected to improve the accuracy of the results.

Economic development level (Pgrp): When the economy develops to a certain stage, it will increase the demand for high-end industries, and then reverse promote the optimization and upgrading of industrial structure. Therefore, Pgrp (per capita GDP) of each region in 2012-2019 is selected as one of the control variables. Because the per capita GDP is too large, we take logarithm in the empirical analysis.

Government intervention level (Govern): Local government financial investment can effectively promote 
the optimization and upgrading of regional industrial structure. Therefore, this paper selects the proportion of local government general budget expenditure in GDP of each province from 2012 to 2019 as one of the control variables.

Trade level (Trade): The impact of international trade on industrial structure is far-reaching. The higher a country's total import and export volume, the more important it will be in the global industrial chain, and the country's industrial structure will be optimized and upgraded. Therefore, the ratio of total import and export volume and GDP of each region from 2012 to 2019 is selected to characterize the level of foreign trade.

Human capital level $(\mathrm{Hc})$ : The rapid development of China's digital economy is partly due to the rapid popularization of higher education in recent years. Therefore, this paper selects the average years of education in various regions from 2012 to 2019 as one of the control variables. The formula for calculating the average length of schooling is as follows: (primary school population $\times 6+$ junior high school population $\times$ $9+$ high school population $\times 12+$ population above junior college $\times 16$ ) / total population over 6 years old.

\subsection{Model construction}

In order to test the above two hypotheses, this paper establishes the following multivariate linear empirical model:

$$
U T S_{i t}=\beta_{0}+\beta_{1} \text { Internet }+\beta_{2} d s+\beta_{i} X_{i t}+\varepsilon_{i t}
$$

Among them, the subscript $\mathrm{i}$ represents different regions, $t$ represents the year, $\beta 0$ represents the constant term of the model, $\beta 1, \beta 2$ represents the regression coefficient of each explanatory variable, $\beta$ i represents the regression coefficient of each control variable, and $\varepsilon_{i t}$ represents the error term.

\section{Empirical results}

\subsection{Descriptive statistics}

Through the description of the whole sample and sub regional samples, we can find that there are great differences between regions. The average and maximum value of the industrial structure upgrading index in the eastern region are higher than those in the central and western regions, and the standard deviation of the industrial structure upgrading index in the eastern region is 0.152 , It shows that there is a significant gap in the upgrading and optimization level of industrial structure among provinces in the eastern region.

By observing the standard deviation of the core explanatory variables, we can find that there are great differences in the development of different regions. The average and maximum values of the eastern region are higher than those of the central and western regions, which indicates that there is a certain regional imbalance in the development of China's digital economy.

In terms of control variables, the level of economic development, human capital and foreign trade in the eastern region is significantly better than that in the central and western regions, indicating that the overall development level of the eastern region is higher. However, in terms of the level of government intervention, the western region has the highest level of intervention, which may be because the western region is limited by geographical location and development conditions, and its own development power and market vitality are relatively insufficient, so it needs the support of the government.

\subsection{Main inspection result}

Firstly, the empirical equation is checked for multiple collinearity, and the results show that there is no multiple collinearity problem; secondly, the Hausmann test is carried out for the panel data model, and the original hypothesis is rejected. Therefore, the fixed effect model should be adopted. Finally, the OLS method is used for the regression analysis of static panel data.

Table 1. Different forms of regression results

\begin{tabular}{|c|c|c|c|}
\hline $\begin{array}{c}\text { Variable } \\
\text { name }\end{array}$ & $\begin{array}{l}\text { Mixed } \\
\text { regression } \\
\text { UTS }\end{array}$ & $\begin{array}{c}\text { Fixed effect } \\
\text { regression } \\
\text { UTS }\end{array}$ & $\begin{array}{c}\text { Random effect } \\
\text { regression } \\
\text { UTS }\end{array}$ \\
\hline \multirow{2}{*}{ Internet } & $7.29 \mathrm{e}-06^{* * *}$ & $1.89 \mathrm{e}-05^{* *}$ & $1.86 \mathrm{e}-05^{* * *}$ \\
\hline & $(2.73 \mathrm{e}-06)$ & $(7.20 \mathrm{e}-06)$ & $(5.79 \mathrm{e}-06)$ \\
\hline \multirow{2}{*}{ ds } & $0.378 * * *$ & $0.154 * *$ & $0.239 * * *$ \\
\hline & $(0.0507)$ & $(0.0658)$ & $(0.0555)$ \\
\hline \multirow{2}{*}{ Pgrp } & $0.107 * * *$ & $0.158 * * *$ & $0.133 * * *$ \\
\hline & $(0.0159)$ & $(0.0422)$ & $(0.0327)$ \\
\hline \multirow{2}{*}{ Govern } & $0.231 * * *$ & $0.735 * * *$ & $0.284 * * *$ \\
\hline & $(0.0367)$ & $(0.221)$ & $(0.0806)$ \\
\hline \multirow{2}{*}{ Trade } & $0.0768 * * *$ & $0.182 * * *$ & $0.137 * * *$ \\
\hline & $(0.0228)$ & $(0.0539)$ & $(0.0285)$ \\
\hline \multirow{2}{*}{$\mathrm{Hc}$} & $0.0206^{* *}$ & 0.000731 & 0.00573 \\
\hline & $(0.00972)$ & $(0.00135)$ & $(0.00442)$ \\
\hline \multirow{2}{*}{ Constant } & $0.885 * * *$ & 0.347 & $0.706 * *$ \\
\hline & $(0.127)$ & $(0.470)$ & $(0.339)$ \\
\hline Obs & 239 & 239 & 239 \\
\hline $\mathrm{R}^{2}$ & 0.833 & 0.737 & 0.7696 \\
\hline
\end{tabular}

respectively, and are robust standard errors in brackets.

From the regression results, we can see that the three different forms of regression results are significant. According to Hausmann test, this paper focuses on the fixed effect model regression results.

From the regression results, the significance of the coefficients of the core explanatory variables are all below 5\%, which effectively verifies the important hypothesis that digital economy can drive the optimization and upgrading of regional industrial structure. Among them, the digital industrialization level is significant at the $5 \%$ level, which indicates that the digital economy has a great impact on the traditional industries and has a profound impact on the upgrading 
and optimization of the industrial structure. Especially with the rapid construction and development of $5 \mathrm{G}$, blockchain and other "new infrastructure", the operation efficiency and development potential of all walks of life have been further improved, helping the industrial structure gradually move to a higher stage and test hypothesis 1 effectively. The significance of industrial digitalization to the optimization and upgrading of industrial structure is also high, which indicates that digital economy can drive the optimization and upgrading of industrial structure by accelerating the digital transformation of traditional industries and creating new formats and models of digital industry, and effectively verifies hypothesis 2 .

As for the control variables, the coefficients of economic development level, government intervention level, foreign trade level and human capital level are generally positive, which indicates that the influence of these variables on the optimization and upgrading of industrial structure is positive, that is, the optimization and upgrading of regional industrial structure will develop with the improvement of these variables.

On the basis of benchmark regression, the samples are divided into eastern, central and western regions for regression, to investigate the impact of digital economy on the upgrading and optimization of industrial structure in different regions.

Table 2. Regional regression results

\begin{tabular}{|c|c|c|c|}
\hline $\begin{array}{c}\text { Variable } \\
\text { name }\end{array}$ & $\begin{array}{c}\text { Eastern } \\
\text { Region } \\
\text { UTS }\end{array}$ & $\begin{array}{l}\text { Central } \\
\text { region } \\
\text { UTS }\end{array}$ & $\begin{array}{c}\text { Western } \\
\text { Region } \\
\text { UTS }\end{array}$ \\
\hline \multirow{2}{*}{ Internet } & $1.10 \mathrm{e}-05^{* * *}$ & $2.91 \mathrm{e}-05^{* *}$ & $4.11 \mathrm{e}-05^{* * *}$ \\
\hline & $(3.59 \mathrm{e}-06)$ & $(1.14 \mathrm{e}-05)$ & $(8.53 \mathrm{e}-06)$ \\
\hline \multirow{2}{*}{ ds } & $0.134 * *$ & 0.161 & 0.0649 \\
\hline & $(0.0538)$ & $(0.166)$ & $(0.0992)$ \\
\hline \multirow{2}{*}{ Pgrp } & $0.128 * * *$ & $0.151 * * *$ & $0.0881 * *$ \\
\hline & $(0.0309)$ & $(0.0533)$ & $(0.0403)$ \\
\hline \multirow{2}{*}{ Govern } & $0.984 * * *$ & $0.519 * *$ & $0.555^{* * *}$ \\
\hline & $(0.181)$ & $(0.211)$ & $(0.183)$ \\
\hline \multirow{2}{*}{ Trade } & $0.112 * * *$ & $-0.336^{*}$ & $0.187^{*}$ \\
\hline & $(0.0402)$ & $(0.180)$ & $(0.108)$ \\
\hline \multirow{2}{*}{$\mathrm{Hc}$} & 0.00103 & $0.0459 *$ & 0.00760 \\
\hline & $(0.00208)$ & $(0.0238)$ & $(0.0165)$ \\
\hline \multirow{2}{*}{ Constant } & $0.718^{*}$ & 0.135 & $1.030^{* *}$ \\
\hline & $(0.360)$ & $(0.561)$ & $(0.407)$ \\
\hline Obs & 88 & 80 & 71 \\
\hline $\begin{array}{l}\text { Number } \\
\text { of pro }\end{array}$ & 11 & 10 & 9 \\
\hline $\mathrm{R}^{2}$ & 0.777 & 0.841 & 0.704 \\
\hline
\end{tabular}

respectively, and are robust standard errors in brackets.

From the regression results, we can see that the impact of digital economy on the upgrading and optimization of industrial structure varies greatly with different regions, that is, there are regional differences.

In the eastern region, digital economy can promote the optimization and upgrading of industrial structure through digital industrialization and industry digitization. The economic strength is relatively strong, and the effect of industrial structure optimization and upgrading is most obvious. This may be closely related to the rapid development of "new infrastructure" in the East. However, for the central and western regions, the digital economy only promotes the optimization and upgrading of industrial structure through digital industrialization, which may be limited by the relatively insufficient power of the development of emerging industries. The impact of digital industrialization on the optimization and upgrading of industrial structure is stronger than that of industry digitization, and digital industrialization has become the core power of the development of digital economy in central and western regions.

\subsection{Robustness test}

The robustness regression mainly uses the method of replacing the main independent variables, replacing the Internet broadband access port (Internet) with the total telecommunications services (TTS). One of the core industries of the digital industry is the telecommunications industry. Therefore, based on the research results at home and abroad, the total telecommunications services (TTS) of each province from 2012 to 2019 is selected as the alternative variable of the digital industry. It can be seen from table 3 that the results are still significant, and the research conclusion remains unchanged.

Table 3. Robust regression results

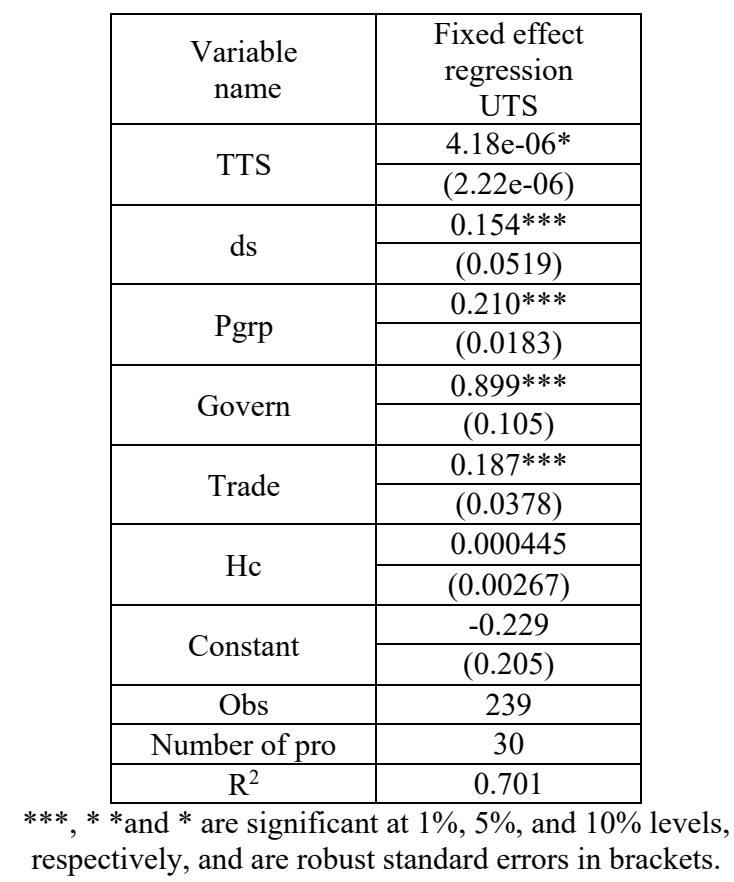

\section{Conclusions and recommendations}

\subsection{Conclusions}

Through literature review and empirical analysis, digital economy does have a far-reaching impact on the upgrading and optimization of industrial structure in digital industrialization and industrial digitization. Both digital industrialization and industrial digitization can 
promote the evolution of industrial structure to a higher form. In the whole country, both of them can obviously promote the upgrading and optimization of industrial structure, but there are regional differences. The eastern region has a greater impact, while the central and western regions are relatively backward.

\subsection{Recommendations}

Digital economy can promote the upgrading and optimization of industrial structure. Therefore, first of all, it is necessary to accelerate and improve the combination and development of digital technology and traditional industries, promote the digital transformation of traditional industries, improve production efficiency, optimize resource allocation, promote the innovation and development of digital technology, and improve the core competitiveness of traditional industries guided by market demand.

Secondly, we should pay attention to the balanced development among regions, and the eastern region should drive the development of the central and western regions. When formulating the relevant policies, we should combine the actual development of the region, according to the regional comparative advantages and shortcomings, study and formulate the digital economy and industrial development planning, give full play to the advantages and make up for the shortcomings. At the same time, the relevant departments should make overall arrangements, improve the relevant deployment, establish and improve the system and mechanism for promoting the development of regional digital economy, reasonably plan the development focus of digital economy in different regions, and realize complementary advantages.

\section{References}

1. Li Y.J., Han P. (2021) The impact of the development of digital economy on the optimization and upgrading of China's industrial structure -- An Empirical Analysis Based on Provincial Panel Data. Research on commercial economy, 06: 183-188.

2. Shen Y.H., Huang H., (2020) Research on the influence of digital economy level on the optimization and upgrading of manufacturing industrial structure -- Based on the panel data of Zhejiang Province from 2008 to 2017. Research on science and technology management, 03:147154.

3. Chen X.H., Zhang H.W., Wu Y.C., (2020) How does digital economy affect the level of industrial structure? Securities Market Herald, 07:20-29.

4. Li X.Z., Wu J.X., (2020) Regional differences of industrial structure transformation and upgrading driven by digital economy. International Economic Cooperation, 04:81-91.
5. Gong Y., (2020) Strategy analysis of industrial structure optimization under the background of digital economy. Research on commercial economy, 12:176-178.

6. Xie T.T., Zhao Y., (2017) Scientific and technological innovation, financial development and Industrial Structure Upgrading -- Based on Bayesian quantile regression analysis. Research on science and technology management,05:1-8. 